\title{
Stosowalność niektórych systemów logicznych do analizy formalnej poprawności wnioskowań dotyczących prawa kanonicznego
}

\author{
Applicability of some logical systems to analyse formal correctness \\ of inferences concerning canon law \\ Применимость некоторых логических систем для анализа формальной \\ корректности выводов, касающихся канонического права \\ ANNA KOZANECKA-DYMEK \\ Dr, Katolicki Uniwersytet Lubelski Jana Pawła II \\ e-mail: akozdym@kul.pl, https://orcid.org/0000-0003-3361-073X
}

\begin{abstract}
Streszczenie: Przykłady zaprezentowane w artykule pozwalają wyrazić przekonanie, że znajomość logiki formalnej może być przydatna w pracy myślowej prawnika kanonisty, zwłaszcza wtedy, gdy nie ma on pewności, czy wyprowadzony przez niego wniosek wynika logicznie z przesłanek. Przeanalizowano formalną poprawność kilku wnioskowań przeprowadzonych w oparciu o kanony, przy użyciu aparatury klasycznego rachunku zdań i sylogistyki, a także wybranych logik nieklasycznych, takich jak np. logika tensalna, logika chronologiczna i logika miejsca.
\end{abstract}

Słowa kluczowe: logika formalna, stosowalność, prawo kanoniczne, formalna poprawność, wnioskowanie

Summary: In the article, concrete examples acknowledge that formal logic can be useful in the work of a lawyer-canonist. Formal correctness is also analysed with several inferences conducted on a basis of canons, using an apparatus of classical propositional calculus and syllogistic, and also selected non-classical logics such as, for example, tense logic, chronological logic, and place logic.

Key words: formal logic, applicability, canon law, formal correctness, inference

Резюме: Приведенные в статье примеры позволяют выразить убеждение, что знание формальной логики может быть полезным в мыслительной работе юриста-канониста, особенно когда он не уверен, следует ли выдвигаемый им вывод, логически из определенных предпосылок. В статье анализируется формальная корректность нескольких выводов, основанных на канонах, с использованием аппарата классического исчисления высказываний и силлогистики, а также отдельных неклассических логик, таких как логика, связанная с грамматической категорией времени («тенсальная логика), хронологическая логика и логика места.

Ключевые слова: формальная логика, применимость, каноническое право, формальная корректность, вывод

\section{Wstęp}

Jeżeli zgodzimy się z tym, że logika formalna może być przydatna do analizy formalnej poprawności wnioskowań przeprowadzanych przez prawników zajmują- 
cych się stanowionym prawem świeckim ${ }^{1}$, to powinnyśmy zgodzić się także z tym, że może być ona przydatna również do analizy formalnej poprawności wnioskowań przeprowadzanych przez prawników kanonistów w oparciu o normy należące do systemu prawa stanowionego przez Kościół.

W niniejszym artykule na konkretnych przykładach spróbuję pokazać, że wiedza z zakresu logiki formalnej może być przydatna osobom studiującym prawo kanoniczne ${ }^{2}$ i, co za tym idzie, absolwentom tego kierunku; innymi słowy, że logika formalna może być użyteczna w pracy myślowej studenta prawa kanonicznego, a także prawnika kanonisty.

Faktem jest, że wrodzony człowiekowi mechanizm oceny poprawności wnioskowania (oparty na intuicji) czasem zawodzi (dzieje się tak nawet w przypadku prostych wnioskowań). W takiej właśnie sytuacji, tj. w razie wątpliwości, czy wyprowadzony wniosek wynika logicznie z przesłanek, można odwołać się do odpowiedniej teorii logicznej, która pomoże w przeanalizowaniu danego wnioskowania. Każde wnioskowanie ma przecież jakąś strukturę, a skoro tak, to da się je zapisać za pomocą symboli odpowiedniego systemu logicznego. Kiedy uzyska się już model danego wnioskowania, można na podstawie logicznych reguł sprawdzić, czy jest ono formalnie poprawne (czy wniosek wynika logicznie z przesłanek), jeśli zaś okaże się, że nie jest - odpowiednio skorygować błąd. Znajomość tego rodzaju narzędzi może okazać się zatem użyteczna (i to nie tylko prawnikom); mogą one po prostu okazać się kiedyś potrzebne.

Przeanalizuję teraz kilka wnioskowań przeprowadzonych w oparciu o kanony ${ }^{3}$ przy użyciu aparatury wybranych systemów logicznych, tj. klasycznego rachunku

1 Kwestią tą autorka zajmowała się w swoich wcześniejszych pracach. Zob. np. A. Kozanecka-Dymek, O możliwości stosowania niektórych systemów 'tense logic' i systemu 'And Then' G. H. von Wrighta w naukach prawnych, Kwartalnik Filozoficzny 2014, t. 42, z. 1, s. 59-74; taż, Logika chronologiczna i jej zastosowania $w$ analizie niektórych rozumowań prawniczych, Analiza i Egzystencja 2014, t. 26, s. 2142; taż, Stosowalność niektórych rozszerzeń tense logic w logicznej analizie rozumowań prawniczych, Kwartalnik Filozoficzny 2015, t. 43, z. 2, s. 25-40; taż, Logika miejsca i jej zastosowania w analizie niektórych rozumowań prawniczych, Analiza i Egzystencja 2016, t. 33, s. 51-68; taż, Logika temporalna i jej zastosowania w naukach prawnych, Studia Philosophica Wratislaviensia 2018, t. 13, nr 2, s. 21-38; taż, Chronological logic i metric tense logic oraz ich przydatność do analizy formalnej poprawności niektórych wnioskowań prawniczych, Kwartalnik Filozoficzny 2018, t. 46, z. 3, s. 5-23.

2 Rozumiane jako dyscyplina naukowa, której przedmiotem są normy należące do systemu prawa kanonicznego, tj. normy prawne wytworzone przez Kościół (łaciński) i w nim obowiązujące.

3 Codex Iuris Canonici auctoritate Ioannis Pauli PP. II promulgatus (25.01.1983 r.), AAS 75(1983), pars II, s. 1-317. Kodeks Prawa Kanonicznego, przekład polski zatwierdzony przez Konferencję Episkopatu, Poznań 1984. Dokładniejsze wyjaśnienie podanych w artykule przykładów opartych na kanonach Kodeksu Prawa Kanonicznego znaleźć można np. w: Komentarz do Kodeksu Prawa Kanonicznego, t. 1-5, red. J. Krukowski, Poznań 2003-2019. 
zdań, sylogistyki oraz następujących logik nieklasycznych: logiki tensalnej, logiki chronologicznej, logiki miejsca i systemu And Then.

Jak wiadomo, na gruncie klasycznego rachunku zdań ${ }^{4}$ występują następujące symbole:

- zmienne: p, q, r ... (które mogą reprezentować zdania proste),

- stałe: $\neg($ nie $), \wedge(i), \vee(l u b), \rightarrow(j e s ́ l i . . .$, to... $), \equiv($ wtedy i tylko wtedy gdy),

- nawiasy.

Przeanalizujmy następujące wnioskowania.

$1 \mathrm{~A}$.

Wiadomo, że jeśli ktoś jest katolikiem5, to w Środę Popielcową i w Wielki Piątek obowiązuje go post ścisły (na podstawie kan. 1251, 1252). Zatem jeśli wiemy o kimś, że jest on katolikiem, wnioskujemy, że w Środę Popielcową i w Wielki Piątek obowiązuje go post ścisły.

Wnioskowanie to przebiegałoby według schematu:

$$
\begin{aligned}
& p \rightarrow q \\
& p \\
& q^{6}
\end{aligned}
$$

$1 \mathrm{~B}$.

Możemy także wnioskować następująco: jeśli ktoś jest katolikiem, to w Środę Popielcową i w Wielki Piątek obowiązuje go post ścisły. Zatem jeśli wiemy o kimś, że w Środę Popielcową i w Wielki Piątek obowiązuje go post ścisły, wnioskujemy, że jest on katolikiem.

To wnioskowanie z kolei przebiegałoby według schematu:

$$
\begin{aligned}
& p \rightarrow q \\
& q \\
& p
\end{aligned}
$$

4 Rachunki logiczne nie będą dokładnie charakteryzowane, gdyż zakłada się, iż czytelnik ma, przynajmniej podstawową, wiedzę o nich. Informacje dotyczące konkretnych systemów, zwłaszcza tych nieklasycznych, znaleźć można m.in. we wspomnianych dalej pracach źródłowych.

5 Między 18 a 60 rokiem życia.

6 Litera p reprezentuje zdanie Ktoś jest katolikiem, a q zdanie W Środę Popielcowa i w Wielki Piątek obowiazuje go post ścisty. 
Większość ludzi nieznających podstaw logiki uznałoby obydwa te wnioskowania za poprawne, chociaż poprawne formalnie jest tylko pierwsze wnioskowanie (widać zatem, że intuicyjny mechanizm oceny poprawności wnioskowań może zawieść nawet $\mathrm{w}$ przypadku tych najprostszych), które przebiega w oparciu o prawo modus ponendo ponens: $(\mathrm{p} \rightarrow \mathrm{q}) \wedge \mathrm{p} \rightarrow \mathrm{q}$, o czym powinien wiedzieć każdy, kto odbył podstawowy kurs logiki.

Podobna sytuacja miałaby pewnie miejsce w przypadku następujących wnioskowań: 2A.

Każdy wierny Kościoła katolickiego jest zobowiązany w niedzielę i w święta nakazane do uczestnictwa we Mszy Świętej (w oparciu o kan. 1247). Skoro zatem Jan Kowalski jest wiernym Kościoła katolickiego, to wniosek z tego, że jest on zobowiązany w niedzielę i w święta nakazane do uczestnictwa we Mszy Świętej.

Schemat tego wnioskowania $\mathrm{z}$ wykorzystaniem symboli sylogistyki, tj.:

- zmiennych: S, P, M (które reprezentują nazwy niepuste) oraz

- stałych: a (każdy... jest ...), e (żaden... nie jest...), i (niektóre... sq̨...), o (niektóre... nie sa...), wyglądałby tak:

$\mathrm{M}$ a $\mathrm{P}$

$\mathrm{S}$ a M

$\mathrm{S}$ a $\mathrm{P}^{7}$

2B.

Każdy wierny Kościoła katolickiego jest zobowiązany w niedzielę i w święta nakazane do uczestnictwa we Mszy Świętej. Każdy diakon Kościoła katolickiego jest zobowiązany w niedzielę i w święta nakazane do uczestnictwa we Mszy Świętej (w oparciu o kan. 276) ${ }^{8}$. Zatem: Każdy diakon Kościoła katolickiego jest wiernym Kościoła katolickiego.

Schemat tego wnioskowania przedstawiałby się tak:

$\mathrm{P}$ a M

$\mathrm{S}$ a M

$\mathrm{S}$ a $\mathrm{P}^{9}$

7 M reprezentuje nazwę wierny Kościoła katolickiego, $\mathrm{P}$ nazwę zobowiązany w niedzielę i $w$ święta nakazane do uczestnictwa we Mszy Świętej, a S nazwę Jan Kowalski.

8 W kan. $276 \$ 2$ jest mowa o codziennym uczestnictwie (a zatem tym bardziej w niedzielę i w święta nakazane).

9 M reprezentuje nazwę zobowiązany w niedzielę i w święta nakazane do uczestnictwa we Mszy Świętej, P nazwę wierny Kościoła katolickiego, a S nazwę diakon Kościoła katolickiego. 
Tutaj również większość ludzi uznałaby pewnie, że obydwa te wnioskowania są poprawne, mimo że jest nim tylko pierwsze - przebiegające w oparciu o tzw. tryb sylogistyczny Barbara: $\mathrm{M}$ a $\mathrm{P} \wedge \mathrm{S}$ a $\mathrm{M} \rightarrow \mathrm{S}$ a $\mathrm{P}$, określany często mianem dictum de omni (łac. twierdzenie o wszystkim).

Oczywiste zatem jest, że jedynie posługując się odpowiednimi narzędziami logicznymi, możemy bezbłędnie oddzielać wnioskowania dedukcyjne, tj. poprawne formalnie, od tych, które nimi nie są. Dlatego też znajomość przynajmniej podstawowych systemów formalnych może okazać się pożyteczna.

Wrócę teraz do klasycznego rachunku zdań, aby zwrócić uwagę na niektóre jego rozszerzenia. Wiadomo, że za pomocą symboli tego rachunku nie da się oddać m.in. czasów gramatycznych, w jakich sformułowane są występujące we wnioskowaniach zdania. Można to jednak zrobić za pomocą symboli logiki tensalnej (tense $\operatorname{logic})^{10}$, na gruncie której, oprócz klasycznych, występują także funktory czasowe:

$\mathrm{P}$ (było kiedyśtak, że...) oraz F (będzie kiedyś tak, że...), a także:

$\mathrm{H}$ (było zawsze tak, że...) oraz G (będzie zawsze tak, że...).

Przeanalizujmy następujące przykłady:

$3 \mathrm{~A}$.

Zawsze będzie tak, że: jeżeli ktoś zostaje ochrzczony, to zostaje wcielony do Kościoła Chrystusowego (na podstawie kan. 96), a zatem: jeśli ktoś zostanie ochrzczony, to zostanie wcielony do Kościoła Chrystusowego. Wnioskowanie to można oddać adekwatnie w następujący sposób:

$$
\overline{\mathrm{G}(\mathrm{p} \rightarrow \mathrm{q})}
$$

3B.

Zawsze będzie tak, że: jeżeli ktoś zostaje ochrzczony, to zostaje wcielony do Kościoła Chrystusowego, a zatem: jeśli ktoś został ochrzczony, to został wcielony do Kościoła Chrystusowego. Schemat wnioskowania:

$$
\begin{aligned}
& \mathrm{G}(\mathrm{p} \rightarrow \mathrm{q}) \\
& \mathrm{Pp} \rightarrow \mathrm{Pq}
\end{aligned}
$$

10 Zob. np. A.N. Prior, Time and Modality, Oxford 1957. Logika tensalna jest jednym z rodzajów logiki temporalnej.

11 Litera p reprezentuje zdanie Ktoś zostaje ochrzczony, a q zdanie Ktoś zostaje wcielony do Kościoła Chrystusowego. 
Wnioskowanie pierwsze jest poprawne i przebiega w oparciu o następujące twierdzenie: $\mathrm{G}(\varphi \rightarrow \psi) \rightarrow(\mathrm{F} \varphi \rightarrow \mathrm{F} \psi)^{12}$. Drugie natomiast jest niepoprawne (byłoby ono poprawne, gdyby przesłanka sformułowana była np. następująco: Zawsze było tak, że: jeżeli ktoś zostaje ochrzczony, to zostaje wcielony do Kościoła Chrystusowego).

Czasy gramatyczne, w jakich sformułowane są zdania występujące we wnioskowaniach, mają duże znaczenie. Różnicę między zdaniami typu: Został ochrzczony, Zostaje ochrzczony, Zostanie ochrzczony można oddać tylko za pomocą symboli logiki tensalnej, zapisując te zdania odpowiednio: Pp, p, Fp (w rachunku zdań trzeba by je wszystkie zapisać tak samo: p).

Metryczna logika tensalna (metric tense logic), nazywana także metryczną logiką czasów gramatycznych ${ }^{13}$, pozwala $z$ kolei wyrazić oprócz tego, że opisywane zdarzenie miało miejsce w przeszłości lub będzie miało miejsce w przyszłości, także to kiedy dokładnie, tj. przed upływem lub po upływie ilu jednostek czasu. Powstała ona bowiem poprzez dołączenie do funktorów P i F dodatkowych symboli:

$m, n$ - które reprezentują nazwy długości interwałów czasowych, a więc de facto pewne liczby określonych jednostek czasu.

Za pomocą symboli tejże logiki można przykładowo zapisać następujące wnioskowania:

$4 \mathrm{~A}$.

Wiadomo, że biskup diecezjalny zobowiązany jest co pięć lat przedstawiać Papieżowi sprawozdanie o stanie powierzonej sobie diecezji (w oparciu o kan. 399 $\$ 1)$. Można na tej podstawie wnioskować na przykład tak: Będzie tak za rok, że (licząc od tego czasu) pięć lat wcześniej biskup przedstawiał Papieżowi sprawozdanie, a zatem: biskup przedstawiał Papieżowi sprawozdanie cztery lata temu (licząc od dziś).

Schemat tego wnioskowania byłby następujący:

$$
\frac{F^{m} P^{n} p}{P^{n-m} p^{14}}
$$

$12 \varphi$ i $\psi$ reprezentują poprawnie zbudowane formuły tense logic.

13 Zob. np. A.N. Prior, Past, Present and Future, Oxford 1967, s. 95-112.

14 Litera p reprezentuje zdanie Biskup przedstawia Papieżowi sprawozdanie, $m$ reprezentuje liczbę 1 , a $n$ liczbę 5 , w związku z tym $n-m$ liczbę 4 . 
4B.

Skoro biskup przedstawiał sprawozdanie Papieżowi cztery lata temu (licząc od dziś), to będzie tak za rok, że (licząc od tego czasu) przedstawiał je pięć lat temu. Schemat:

$$
\frac{\mathrm{P}^{m} \mathrm{p}}{\mathrm{F}^{n} \mathrm{P}^{m+n} \mathrm{p}^{15}}
$$

Wnioskowanie 4A jest dedukcyjne, tj. formalnie poprawne, i przebiega w oparciu o aksjomat: $\mathrm{F}^{m} \mathrm{P}^{n} \varphi \rightarrow \mathrm{P}^{n-m} \varphi$ dla $\mathrm{n} \geq \mathrm{m}$.

Rozszerzeniem rachunku zdań jest także tzw. logika topologiczna (topological logic), na gruncie której występuje funktor P służący do tworzenia formuł typu: $\mathrm{Pa}$ (p) odczytywanych: „jest tak w pozycji a, że p”; „p jest realizowane w pozycji a”. Zmienna a może reprezentować określenie różnych pozycji, np. w czasie lub w przestrzeni, w których realizowane są stany rzeczy, zdarzenia, opisywane przez zdania. Szczególną interpretacją logiki topologicznej jest logika chronologiczna (chronological logic), na gruncie której, oprócz symboli klasycznej logiki, występują:

- zmienne czasowe: $t, t_{1}, t_{2} \ldots$ (reprezentujące określenia różnych pozycji w czasie) oraz

- funktor tzw. realizacji czasowej R, za pomocą którego można wyrazić, że $w$ takim a takim czasie jest tak a tak ${ }^{16}$.

Formułę Rt (p) odczytamy: „jest tak w czasie $t$, że p”; „p jest realizowane w czasie $t$ ".

$5 \mathrm{~A}$.

Wiadomo, że jeżeli w czasie $t$ wierny znajduje się w niebezpieczeństwie śmierci ${ }^{17}$ i nie trwa uparcie w jawnym grzechu ciężkim, to wolno mu w tym czasie udzielić sakramentu namaszczenia chorych (na podstawie kan. $1004 \$ 1,1007$ ). Skoro więc okazałoby się, że jakiś wierny w czasie $t$ znajduje się w niebezpieczeństwie śmierci i w tym samym czasie $t$ nie trwa uparcie $w$ jawnym grzechu ciężkim, to można

15 Litera p reprezentuje zdanie Biskup przedstawia Papieżowi sprawozdanie, $m$ reprezentuje liczbę 4, a $n$ liczbę 1 , w związku z tym $m+n$ liczbę 5 .

16 Zob. np. N. Rescher, Topics in Philosophical Logic, Dordrecht 1968, s. 196-228 oraz N. Rescher, A. Urquhart, Temporal Logic, New York 1971.

17 Na skutek choroby lub starości. 
wywnioskować z tego, że wolno mu w tym czasie udzielić sakramentu namaszczenia chorych. Schemat podanego wnioskowania miałby postać:

$$
\begin{aligned}
& \mathrm{R} t(\mathrm{p} \wedge \sim \mathrm{q}) \rightarrow \mathrm{R} t(\mathrm{r}) \\
& \mathrm{R} t(\mathrm{p}) \wedge \mathrm{R} t(\sim \mathrm{q})
\end{aligned}
$$

$$
\mathrm{R} t(\mathrm{r})^{18}
$$

Przedstawione wnioskowanie jest dość proste, ale chodzi tu o pokazanie, że to na gruncie chronological logic można udowodnić, że jest ono poprawne. $\mathrm{W}$ dowodzie korzystamy z aksjomatu: $\mathrm{R} t(\mathrm{p} \wedge \mathrm{q}) \equiv \mathrm{R} t(\mathrm{p}) \wedge \mathrm{R} t(\mathrm{q})$. Zwróćmy uwagę, że użycie zmiennych czasowych odgrywa $\mathrm{w}$ tego rodzaju wnioskowaniach istotną rolę, gdyż wskazują one, że chodzi o ten sam lub inny czas. Niepoprawny byłby więc np. schemat:

$5 B$.

$\mathrm{R} t(\mathrm{p} \wedge \sim \mathrm{q}) \rightarrow \mathrm{R} t(\mathrm{r})$

$\mathrm{R} t(\mathrm{p}) \wedge \mathrm{R} t_{1}(\sim \mathrm{q})-$ zmienna $t_{1}$ wskazuje, że ten stan rzeczy zachodzi w innym czasie niż pozostałe

$$
\mathrm{R} t(\mathrm{r}) \text { - nie wynika }
$$

Inną ważną interpretacją logiki topologicznej jest tzw. logika miejsca (place logic). Na jej gruncie, oprócz klasycznych symboli, występują także:

- zmienne: $a, b, c \ldots$ (reprezentujące określenia różnych miejsc w przestrzeni) oraz

- funktor P, przy użyciu którego można wyrazić, że $w$ takim a takim miejscu jest tak a tak ${ }^{19}$.

Formułę $\mathrm{P} a(\mathrm{p})$ odczytamy: ,jest tak w miejscu $a$, że p”; „p jest realizowane w miejscu $a$ ".

$18 \mathrm{~W}$ podanym schemacie litera $\mathrm{p}$ reprezentuje zdanie Wierny znajduje się w niebezpieczeństwie śmierci, q zdanie [Wierny] trwa uparcie w jawnym grzechu ciężkim, $\mathrm{r}$ zdanie Wolno udzielić mu sakramentu namaszczenia chorych, zaś $t$ reprezentuje określenie czasu, w jakim te stany rzeczy miałyby miejsce.

19 Zob. np. N. Rescher, J. Garson, Topological Logic, The Journal of Symbolic Logic 1968, t. 33, nr 4, s. 537. 
Przy użyciu tego rodzaju symboli można sformalizować przykładowo takie wnioskowanie:

$6 \mathrm{~A}$.

Tułacze podlegają ustawom - tak powszechnym, jak i partykularnym - obowiązującym w miejscu przebywania (kan. $13 \$ 3$ ). Zatem: jeśli w miejscu a przebywa tułacz T, a w miejscu $a$ obowiązuje ustawa $\mathrm{U}$, to podlega on w tym miejscu ustawie $\mathrm{U}$. Wiedząc więc, że w określonym miejscu $a$ przebywa tułacz $\mathrm{T}$ i obowiązuje ustawa U, wnioskujemy, że podlega on w tym miejscu tej ustawie U.

Schemat formalny miałby postać:

$$
\begin{aligned}
& \mathrm{Pa}(\mathrm{p}) \wedge \mathrm{P} a(\mathrm{q}) \rightarrow \mathrm{P} a(\mathrm{r}) \\
& \mathrm{Pa}(\mathrm{p} \wedge \mathrm{q}) \\
& \overline{\mathrm{P} a(\mathrm{r})^{20}}
\end{aligned}
$$

Choć to wnioskowanie także jest proste, to na gruncie place logic można udowodnić, że jest ono poprawne. W dowodzie korzystamy z aksjomatu: $\mathrm{P} a(\mathrm{p} \wedge \mathrm{q}) \equiv \mathrm{P} a(\mathrm{p}) \wedge \mathrm{P} a(\mathrm{q})$. Przy formalizacji tego rodzaju wnioskowań istotne jest również użycie zmiennych reprezentujących nazwy pozycji w przestrzeni, gdyż zmienne te wskazują, które stany rzeczy czy zdarzenia zachodzą dokładnie $\mathrm{w}$ tym samym miejscu, a które zachodzą w innych miejscach. Niepoprawny byłby więc np. schemat:

$6 \mathrm{~B}$.

$\mathrm{P} a(\mathrm{p}) \wedge \mathrm{P} a(\mathrm{q}) \rightarrow \mathrm{P} a(\mathrm{r})$

$\mathrm{P} b(\mathrm{p} \wedge \mathrm{q})-$ zmienna $b$ wskazuje, że ten stan rzeczy zachodzi w innym miejscu niż pozostałe

$\mathrm{P} a(\mathrm{r})$ - nie wynika

Systemem, na który także warto zwrócić uwagę w kontekście omawianych tu zagadnień, jest system And Then skonstruowany w 1966 r. przez G.H. von Wrighta ${ }^{21}$.

20 Litera $\mathrm{p}$ reprezentuje zdanie Tułacz $T$ przebywa, q zdanie Ustawa U obowiązuje, $\mathrm{r}$ zdanie [Tułacz] podlega ustawie $U$, zaś a reprezentuje określenie miejsca, w którym zachodziłyby te stany rzeczy.

21 G.H. von Wright, And Then, Commentationes Physico-Mathematicae 1966, t. 32, nr 7, s. 1-11. 
W systemie tym, również będącym rozszerzeniem rachunku zdań, występuje dodatkowo funktor temporalny:

T - odczytywany: i potem.

Formuly typu: $\mathrm{p}$ T q odczytuje się zatem: $\mathrm{p} i$ potem $\mathrm{q}$.

Kolejność, w jakiej występują argumenty tego funktora, ma duże znaczenie (wyrażenie: $\mathrm{p} \mathrm{T}$ q nie jest bowiem równoważne wyrażeniu: $\mathrm{q} \mathrm{T}$ p). Funktor $\mathrm{T}$ jest funktorem tzw. koniunkcji uczasowionej (asymetrycznej). Pełni ważną rolę, ponieważ za jego pomocą można adekwatnie wyrażać następstwo czasowe.

Przeanalizujmy poniższe wnioskowanie:

7A.

Jeżeli ktoś zawarł małżeństwo, a potem stwierdzono nieważność tego małżeństwa, to osoba ta może ponownie wstąpić w związek małżeński (w oparciu o kan. 1085 $\S 2)$. Zatem w sytuacji gdy wiemy, że ktoś zawarł małżeństwo, a potem stwierdzono jego nieważność, wnioskujemy, że osoba ta może ponownie wstąpić w związek małżeński.

Wnioskowanie to można sformalizować w następujący sposób:

$$
\begin{aligned}
& \mathrm{p} \mathrm{T} \mathrm{q} \rightarrow \mathrm{r} \\
& \mathrm{p} \mathrm{T} \mathrm{q} \\
& \overline{\mathrm{r}^{22}}
\end{aligned}
$$

Taka formalizacja jednoznacznie wskazuje, że najpierw miało miejsce zdarzenie opisywane przez zdanie reprezentowane przez literę p, a potem zdarzenie opisywane przez zdanie reprezentowane przez literę q. Niepoprawny byłby więc schemat:

$7 \mathrm{~B}$.

$$
\begin{aligned}
& \mathrm{p} \mathrm{T} \mathrm{q} \rightarrow \mathrm{r} \\
& \mathrm{qT} \mathrm{p}
\end{aligned}
$$

$\mathrm{r}$ - nie wynika

Druga przesłanka: q T p wyraża inną sytuację niż zdanie zapisane jako: p T q. Zapis: q T p wskazuje, że najpierw stwierdzono nieważność czyjegoś małżeństwa (q),

$22 \mathrm{~W}$ schemacie tym litera p reprezentuje zdanie Ktoś zawarł małżeństwo, q reprezentuje zdanie Stwierdzono nieważność małżeństwa [tej osoby], zaś $\mathrm{r}$ reprezentuje zdanie Osoba ta może ponownie wstapić w związek małżeński. 
a potem osoba ta zawarła małżeństwo (p). Z tej i z pierwszej przesłanki ( $\mathrm{p} \mathrm{T} \mathrm{q} \rightarrow \mathrm{r}$ ) nie wynika logicznie wniosek, że osoba ta może ponownie wstąpić w związek malżeński (r).

Kolejność zdarzeń ma tutaj bardzo duże znaczenie. Nie da się jej odpowiednio wyrazić na gruncie klasycznej logiki (gdzie koniunkcja jest symetryczna) ${ }^{23}$, ale, jak pokazano, można to zrobić, korzystając z systemu temporalnego And Then.

\section{Zakończenie}

Tak jak wspomniano we wstępie, zdarza się, że wrodzony nam mechanizm oceny poprawności wnioskowań (oparty na intuicji) zawiedzie i nie mamy pewności, czy wyprowadzony wniosek rzeczywiście wynika logicznie z przesłanek. Możemy wtedy sięgnąć do narzędzi dostarczanych przez logikę formalną. Skoro istnieją tego rodzaju narzędzia, warto z nich korzystać. Dotyczy to zwłaszcza tych osób, których zawód w znacznej mierze polega na logicznym rozumowaniu, a więc także m.in. prawników kanonistów. Przy czym znajomość klasycznej logiki nie zawsze wystarcza, dlatego też wskazana jest znajomość przynajmniej niektórych logik nieklasycznych, żeby w razie potrzeby móc je zastosować ${ }^{24}$.

Pamiętać jednak trzeba, by korzystać z systemów adekwatnych, tj. systemów spełniających dwa podstawowe warunki: dostarczających właściwego języka (czyli takiego, który umożliwiałby formalizację określonych zwrotów występujących we wnioskowaniach prawniczych) i jednocześnie wartościowych poznawczo (czyli takich, których tezy są zadaniami prawdziwymi w modelu określonego aspektu rzeczywistości) ${ }^{25}$.

W artykule przedstawiona została analiza formalnej poprawności kilku wnioskowań przeprowadzonych $\mathrm{w}$ oparciu o kanony, przy użyciu aparatury wybranych systemów logicznych, tj. klasycznego rachunku zdań, sylogistyki oraz niektórych adekwatnych systemów nieklasycznych, aby pokazać, że logika formalna może być użyteczna w pracy myślowej studenta prawa kanonicznego i prawnika kanonisty. Oczywiście, oprócz tych zaprezentowanych, można stosować do tego celu także inne systemy, m.in. rachunek predykatów, logikę deontyczną czy logiki

23 W klasycznej logice $(\mathrm{p} \wedge \mathrm{q}) \equiv(\mathrm{q} \wedge \mathrm{p})$.

24 Oczywiście taka potrzeba może nigdy nie zajść, ale nie jest wykluczone, że może jednak kiedyś zajść.

Przykładowo w przypadku logiki temporalnej tezy systemu poznawczo wartościowego są prawdziwe w fizykalnym modelu czasu. Por. A. Kozanecka-Dymek, Logiki tensalne, w: Jedność i wielość logik modalnych, red. M. Tkaczyk, Lublin 2019, s. 119-122. 
niemonotoniczne (ich stosowalność do analizy formalnej poprawności wnioskowań przeprowadzanych w dziedzinie prawa kanonicznego może stanowić materiał na kolejny artykuł).

\section{Bibliografia}

Codex Iuris Canonici auctoritate Ioannis Pauli PP. II promulgatus (25.01.1983 r.), AAS 75(1983), pars II, s. 1-317. Kodeks Prawa Kanonicznego, przekład polski zatwierdzony przez Konferencje Episkopatu, Poznań 1984.

Jedność i wielość logik modalnych, red. M. Tkaczyk, Lublin 2019.

Komentarz do Kodeksu Prawa Kanonicznego, t. 1-5, red. J. Krukowski, Poznań, 2003-2019.

Kozanecka-Dymek A., 'Chronological logic' i 'metric tense logic' oraz ich przydatność do analizy formalnej poprawności niektórych wnioskowań prawniczych, Kwartalnik Filozoficzny 2018 , t. 46 , z. 3.

Kozanecka-Dymek A., Logika chronologiczna i jej zastosowania w analizie niektórych rozumowań prawniczych, Analiza i Egzystencja 2014, t. 26.

Kozanecka-Dymek A., Logika miejsca i jej zastosowania w analizie niektórych rozumowań prawniczych, Analiza i Egzystencja 2016, t. 33.

Kozanecka-Dymek A., Logika temporalna i jej zastosowania w naukach prawnych, Studia Philosophica Wratislaviensia 2018, t. 13, nr 2.

Kozanecka-Dymek A., O możliwości stosowania niektórych systemów 'tense logic' i systemu 'And Then' G. H. von Wrighta w naukach prawnych, Kwartalnik Filozoficzny 2014, t. 42, z. 1.

Kozanecka-Dymek A., Stosowalność niektórych rozszerzeń tense logic w logicznej analizie rozumowań prawniczych, Kwartalnik Filozoficzny 2015, t. 43, z. 2.

Prior A.N., Past, Present and Future, Oxford 1967.

Prior A.N., Time and Modality, Oxford 1957.

Rescher N., Topics in Philosophical Logic, Dordrecht 1968.

Rescher N., Garson J., Topological Logic, The Journal of Symbolic Logic 1968, t. 33, nr 4.

Rescher N., Urquhart A., Temporal Logic, New York 1971.

von Wright G.H., And Then, Commentationes Physico-Mathematicae 1966, t. 32, nr 7. 